
\title{
Pregnant smokers: Room for improvement
}

\section{Hanne Tønnesen}

doi.org/10.29102/clinhp.15001

\section{About the AUTHOR}

\section{Editor-in-Chief}

Director, WHO-CC, Clinical Health Promotion Centre, Bispebjerg \& Frederiksberg Hospital, University of Copenhagen, Copenhagen, Denmark.

Professor at Lund University, Skåne University Hospital, Malmö, Sweden

Professor, University of Southern Denmark CEO, International $\mathrm{HPH}$ Secretariat President, Clinical Health Promotion Society

Contact: Hanne Tønnesen Hanne.Tonnesen@regionh.dk

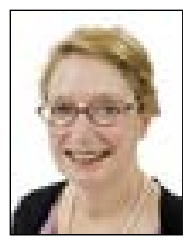

Clin Health Promot 2015; 5:3
The issue of pregnant smokers is a social and health problem, which has not received substantial attention.

Smoking during pregnancy is associated with significant problems for the foetus, the child and the mother. Firstly, smoking increases the risk of ectopic pregnancies, spontaneous abortion, perinatal mortality, placental abruption, conjugate malformations as well as preterm birth, low birth weight, growth reduction, and sudden infant death syndrome. Secondly, the mother experiences more complications during pregnancy and delivery. Thirdly, maternal smoking has consequences for the child after being born, such as hospitalisation within the first year of life and behavioural disturbances and lifestyle problems during childhood. $(1 ; 2)$

\section{Smoking rates}

Smoking during pregnancy is still a significant problem; even in a country with low smoking rates like Sweden about 8\% smoke during pregnancy (3). On the plus side, many women quit smoking before getting pregnant, where as many as 50$60 \%$ of pregnant smokers successfully quit smoking in the three months period prior to pregnancy. However, about $10 \%$ of the pregnant women reporting to quit during pregnancy still have positive CO measurement indicating continuous smoking. The over-reporting increases late in the pregnancy to about $17 \%$ as reported among Canadian pregnant women (4).

\section{Smoking cessation intervention}

Quitting smoking before pregnancy or in the first trimester is followed by normalisation of the risk of smoking related fetal complications (1). This is the reason why many international, national and local policies and programmes actively target smoking during pregnancy.
Overall, the effect of smoking cessation intervention for pregnant women is as low as $6 \%(5)$. The more effective programmes include incitements (5) and intensive interventions over 6 weeks (6). The 6 weeks Gold Standard Programme is implemented as the standard intervention in Denmark and has recently showed similar high abstinence rates in pregnant compared to non-pregnant women. Overall, about $32 \%$ of the women had succeeded in not smoking from end of the programme to the 6 months follow-up.

\section{Responsibility}

Doctors, midwifes and all other health professionals meeting women who are pregnant or planning for pregnancy have a strong responsibility to identify smokers and to offer the most effective smoking cessation programmes. This will allow both the child and the mother to benefit from early smoking cessation by avoiding the consequences associated with maternal smoking. Policy-makers are responsible for establishing the necessary policies for implementation as well as the relevant action plans and frameworks for implementation and quality assurance to followup its effects. The sooner, the better!

\section{References}

(1) Cnattingius S. The epidemiology of smoking during pregnancy: Smoking prevalence, maternal characteristics, and pregnancy outcomes. Nicotine Tob Res 2004; 6:125-40.

(2) Shi Y, De Groh M, Morrison H. Perinatal and early childhood factors for overweight and obesity in young Canadian children. Can J Public Health 2013; 104:69-74.

(3) Baba S, Wilkström AK, Stephansson O, Cnattingius S. BJOG 2012; 120:456-62.

(4)Tong VT, Althabe F, Alemán A et al. Accuracy of self-reported smoking cessatation during pregnancy. Acta Obstet Gynecol Scand 2015; 94:106-11.

(5) Lumley L, Chamberlain C, Dowswell, Oliver S, Oakley L, Watson L. Interventions for promoting smoking cessation during pregnancy. Cochrane Database Syst Rev 2009: CD001055.doi

(6) Rasmussen M, Heitmann BL, Tønnesen H. Effectiveness of the Gold Standard Programmes (GSP) for Smoking Cessation in Pregnant and Non-Pregnant Women. Int. J. Environ. Res Public Health 2013; 10:3653-66. 